\title{
Ecological Sustainability of Silk Manufacturing Segment in Indian Ecosphere and future growth prospects from an economic perspective
}

\author{
Divya Nandini Sharma ${ }^{1}$, Lakheshwar ${ }^{2}$ \\ ${ }^{1}$ Guest Assistant Professor, Department of Commerce, Kishori Mohan Tripathi Government Girl’s College, \\ Raigarh, Chhattisgarh \\ ${ }^{2}$ Research Scholar, Govt. V. Y. T. PG Autonomous College, Durg, Chhattisgarh
}

\begin{abstract}
The silk manufacturing segment is one of the prominent commercial arenas which are directly related to nature. The variants of natural silk available in Indian ecosphere are 'Mulberry', 'Tasar', 'Muga' and 'Eri' with 'Mulberry' covering a major portion of the market and the latter ones covering remaining one tenth portion of the market which are extremely rare to find and fetch high prices. The silk manufacturing segment has been significant from the economic perspective because of its high profit yielding potential which contributes in augmenting national income and providing employment to large number of people which contributes in augmenting per capita income and raising living standard. Another significance of silk manufacturing segment is that it attracts significant foreign exchange for the country. Silk manufacturing, as lucrative as it seems, has undergone a revolutionary phase owing to rapid technological up gradations. The manufacturing techniques, quality of produce and demand trends are also changing along with these innovations. The traditional manufacturing techniques were devoid of present day innovations but it cannot be said that they were in total harmony with sustainability. The present day techniques which are influenced by technological up gradations also have their own pros and cons. This study aims to study the synchronism and harmony between silk manufacturing and ecological sustainability along with analyzing the positive and negative impacts of silk manufacturing from sustainability point of view, the effect of technological up gradations on sustainability \& economic development of the industry. This analysis studies the degree of association between sustainability and economic development along with analyzing future growth prospects for the segment keeping the objective of sustainability in consideration.
\end{abstract}

Keywords: Silk manufacturing, ecological sustainability, synchronism, economic development, growth prospects.

\section{INTRODUCTION}

The silk manufacturing segment is one of the highly profitable manufacturing segments worldwide. The Indian ecosphere ranks next to China in terms of silk production. Another distinctive feature of silk manufacturing in India is the variety of silk manufactured in India. India is the only ecosphere in the Indian subcontinent where all the variants of silk are manufactured, 'Mulberry', 'Muga', 'Eri' and 'Tasar'.

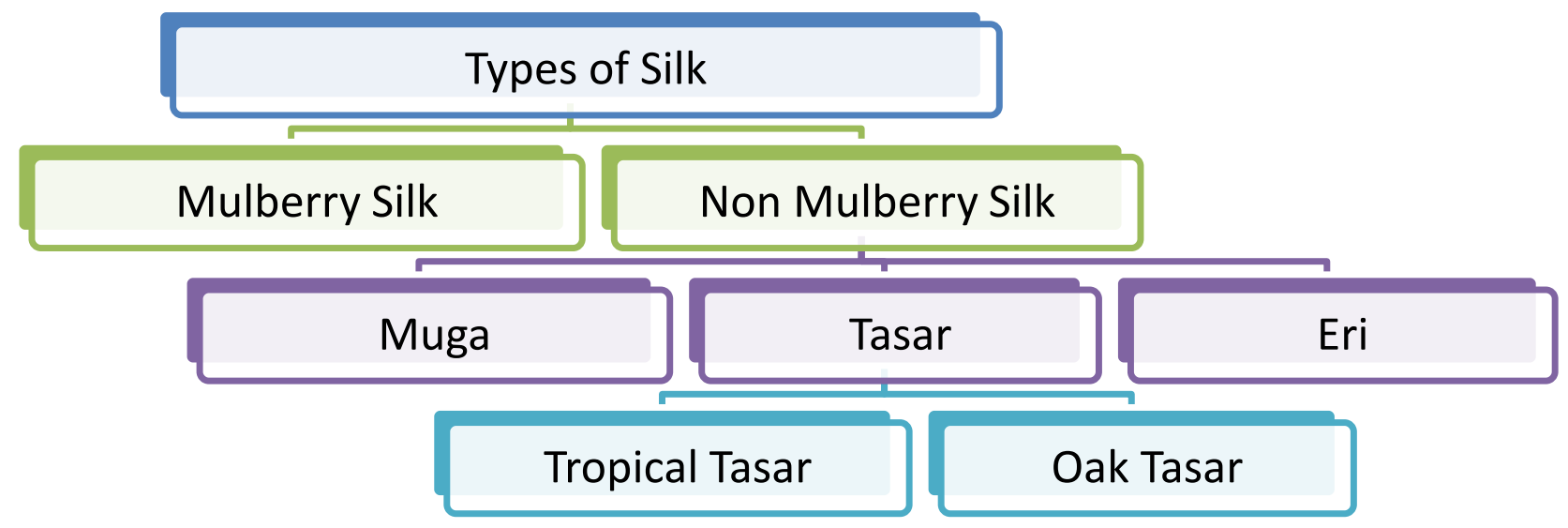

Figure 1: A bifurcation of Types of Silk from commercial perspect 


\section{International Advanced Research Journal in Science, Engineering and Technology}

Vol. 8, Issue 10, October 2021

\section{DOI: $10.17148 /$ IARJSET.2021.81029}

The garment sector of Indian ecosphere is flooded with silk products. Silk carries relevance not only in garment sector but also in the form of medical dressings, insulating coils for telephones, parachutes in the military, gun powder wags, holograms etc. Silk is a fiber produced from a natural protein that is the larva of silkworm. Among all the fibers available in the market, Silk is the only one which is natural. Silk fiber is extracted from filaments of cocoons. The filament in one cocoon can be up to 1000 yards. Initially originated from China, its manufacturing covers a very less portion of the global market but it is a significantly profitable segment. There are ample evidences in history that silk was traded for other commodities which created a large network for trade which is known as the 'silk road'. It has significant contribution in international business and evolving global culture.

When we try to understand the implications of sustainability in the backdrop of silk industry, there are different issues in the context of agriculture, rights of animals, water conservation, pollution and the human resources involved. In a general sense, Silk is a fibre which is comparatively more sustainable. However, with evolutions in the processes sustainability issues can arise. The issues arising in the context of sustainability of silk manufacturing are further dealt with.

\section{OBJECTIVES OF THE STUDY}

The following study is carried out to:

- $\quad$ Analyse the sustainability issues concerning silk manufacturing sector.

- $\quad$ Understand sustainability from Economic perspective.

- $\quad$ Analyse future growth prospects of silk manufacturing segment.

\section{LITERATURE REVIEW}

'Sustainability' has been defined in various journals belonging to different disciplines. In common parlance, sustainability implies satisfying the requirements of the present without letting our future generations compromise to meet their requirements (Brundtland, 1987) The concept of adopting sustainability implies sustainability from all perspectives. The silk manufacturing segment is a very lucrative segment attracting high profitability and foreign exchange.

A research on 'Indian Silk Industry in the Global Scenario' was carried out by Dr. R. Anitha which focused on the evolutions in silk production methods and reforms in marketing as well as further processing in the production method and the effect of these evolutions in growth of the industry. A research entitled, 'Sustainable Silk Production' was carried out by Thangavel, Karthik and R. Rathinamoorthy which studies the sustainability concerns in silk manufacturing along with the ethical and moral aspects. This research also discussed methods to ensure sustainability by applying sustainable alternatives and spider silk.

\section{RESEARCH METHODOLOGY}

This research follows a descriptive style and is based on secondary sources. The secondary information is sourced from annual reports of central silk board, books, magazines and relevant sites.

\section{SILK MANUFACTURING IN INDIA}

The conventional manufacturing techniques are not much deviated from the current manufacturing techniques. Involving use of simplified technology which does not require any highly skilled operator, it is a feasible option even for less educated farmers. Another aspect that increases its viability is that it provides enough return in a short span of time. The machinery required by silk manufacturing is also simplified and less sophisticated.

The essence of silk manufacturing are mulberry plants. These plants do not require specific soil quality or temperature for plantation purposes. The plantation of these plants can be done in the forest, hilly areas or rainfed areas. A very significant advantage of Mulberry plants is that they can exist even if there are drought conditions. There are other varieties of silk also apart from Mulberry. Those varieties are rarely available because that kind of silk manufacturing is maximum undertaken by Tribals. The Indian ecosphere is characterized as agriculture based and dependent on seasons, where silk manufacturing fits easily. From the economic perspective, India stands next to China in silk production and is the largest consumer of silk. The manufacturing of silk is referred to by the term 'sericulture'. The manufacturing of silk is a segment which does not require huge investment and also provides for ample employment opportunities. There are certain properties of silk which distinguish it from other artificial fibers. 


\section{International Advanced Research Journal in Science, Engineering and Technology}

Vol. 8, Issue 10, October 2021

\section{DOI: 10.17148/IARJSET.2021.81029}

- $\quad$ No other fiber originated in a natural way is as strong as silk.

- It can be colored with dyes and is feasible for printing color patterns also.

- It is not too stretchable and wrinkles easily.

- An important characteristic is that it is apt according to changes in temperature, cool in warm weather and warm in cool weather.

- It is a renewable and biodegradable resource which uses minimum amount of water, chemicals and energy.

- It does not enjoy a very large portion of the market but it possesses a large portion of the profits.

\section{SUSTAINABILITY CONCERNS AND ADDRESSING THEM}

Sustainability is concerned with satisfying the needs of the current time without compromising the requirements of the future. There are three pillars that are primal instruments for sustainability: social, ecological and economic. Sustainability can be taken care of by reducing the emission of pollutants, applying renewable alternatives and supporting sustainability. In the context of silk manufacturing, which is a fundamentally natural process, meeting sustainability requirements is not an enormous challenge. But sustainability cannot be limited to formal definitions, it has certain ethical and moral aspects also which are often ignored in silk manufacturing. The challenges posed by silk manufacturing towards sustainability are discussed subsequently.

The manufacturing process of the most elegant and sought after 'silk' requires killing of silkworms in their cocoons themselves. The cocoons are a protective covering for the silkworm but after extraction of fibre, there are no chances that the silkworms would live to turn into a moth. This is unethical and totally opposite to animal rights. However, other variants of silk, 'wild silk' i.e. Tasar, Eri, Muga are preferred alternatives to traditional silk which does not involve killing of the silkworm. In the manufacturing of wild silk, the silkworms are allowed to transform into a moth and after the moth means the cocoon, further silk extraction is carried out. Another alternative available is 'Peace Silk' or 'Ahimsa Silk' which is quite non-violent, in which the moths are allowed to get out from the cocoons. But the moth most commonly used in commercial silk manufacturing is the 'Bombyx mori moth' which is least likely to survive after leaving the cocoon.

The first sustainability concern is use of fertilizers in mulberry farming. Using chemical preparations in the form of pesticides and fertilizers is also toxic to the environment and sustainability. Too much use of pesticides and fertilizers can cause an increase in chemical components in water bodies which is also known as eutrophication especially in the Indian ecosphere, where subsidies are provided for procuring fertilizers and electricity, this is a major issue for concern. A single Mulberry trees is able to feed a hundred silkworms and on an average, 3000 cocoons are required for one yard of fabric, it will need an enormous number of Mulberry trees. Consumption of water is also a major sustainability concern not only for silk manufacturing but also for other segments. If an enormous number of Mulberry trees are required, their plantation would require that much water as well. An appropriate solution could be to avoid excessive use of fertilizers and pesticides and increasing dependency on natural rainfall for mulberry plants. Apart from depending on natural rainfall, treatment and recycling of water can also be done to ensure that the water released into the external environment is not toxic.

Energy consumption is another aspect of sustainability that carries relevance in silk manufacturing. However, silk manufacturing does not require an enormous amount of energy as compared to other manufacturing activities. Energy is consumed in the transportation of materials, controlling temperature and heating water. The heating of water is required because the manufacturing process involves boiling the cocoons. But if sustainability is concerned, it should be ensured that energy efficiency is practice and a rational use of energy is made.

A very major factor causing an adverse effect on sustainability is the use of toxins in silk manufacturing. There are several chemicals used to remove infections in the overall process of manufacturing, disinfectants made up of bleach powders and other chemicals which are toxic. The cleaning process of silk also requires the use of chemicals. The manufacturing of silk does not require an enormous amount of toxic chemicals therefore, the threat is relatively less. But the silk manufacturing segment makes use of dyes in a large proportion. Natural dyes are the best-suited products for or a natural textile like silk but the market is overloaded by silk coloured using chemical dyes. More sustainable and natural dyes should be opted and untreated water should not be mixed with other water bodies without treating properly. 
Vol. 8, Issue 10, October 2021

DOI: $10.17148 /$ ARJSET.2021.81029

AN ECONOMIC PERSPECTIVE

According to the estimates, the fiscal year 2021 witnessed a $5.8 \%$ shortfall in raw silk production to around 33 thousand metric tons in FY 21 as compared to FY 20 with the highest produce comprising of mulberry silk.

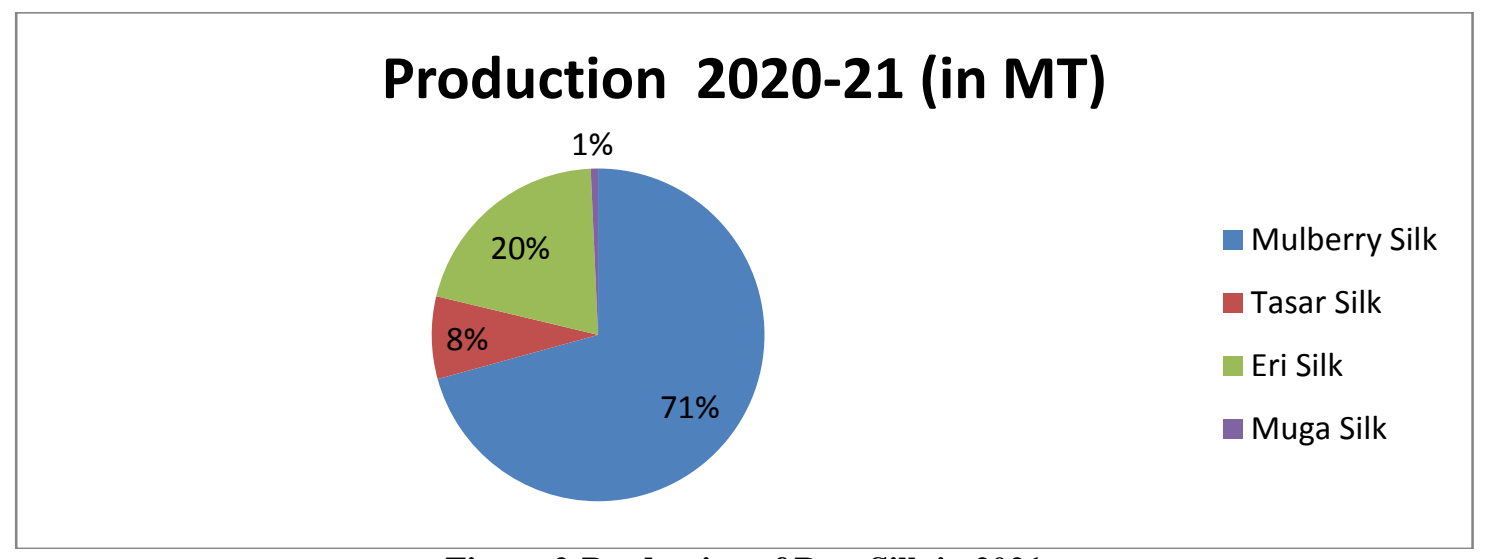

Figure 2:Production of Raw Silk in 2021

The above chart demonstrates that the manufacturing of silk in 20-21 was 33,739 metric tons, comprising of Mulberry silk 23,860 metric ton, Tasar silk 2,705 metric ton, Eri silk 6,935 metric ton and Muga Silk 239 metric ton. The total produce of raw silk in 2021 witnessed the highest production of Mulberry Silk around 24 thousand metric tons and the remaining 9 metric tons was covered by wild silk also known as 'Vanya Silk' with the state of Karnataka as the top producer of silk. If the manufacturing of silk is studied from the geographical point of view, Northeast is the only state which produces all varieties of silk with 18 percent share in total manufacturing. The states which are leaders in silk manufacturing are Karnataka, Andhra Pradesh, Assam, West Bengal, Jharkhand and Tamil nadu.

The decrease in the amount of produce by the silk manufacturing segment has been largely owing to the COVID-19 pandemic. The production of raw silk in the Indian ecosphere consisted of manufacture of bivoltine raw silk $6,772 \mathrm{MT}$ which was $3.4 \%$ less than previous year, the Vanya silk comprising of Tasar which witnessed a decrease of $13.8 \%$, Eri witnessing decrease of $3.7 \%$ and Muga witnessing a decrease of $0.8 \%$ as compared to the previous year. The earnings of the segment through exports in the year 20-21 were Rs. 1418.97 crores. From the employment generation perspective, silk manufacturing generated 8.7 million employment which witnessed $7.4 \%$ decrease compared to previous year.

\section{RESULTS AND DISCUSSION}

Concerning sustainability, silk which is considered as one of the most lustrous, luxurious and marvelous fabric, with Indian ecosphere as its production and consumption hub, involves a process which is equally cruel and unethical. Sustainability cannot be limited to providing for future generations, the scope of sustainability also includes animal rights. Animal rights is the basic thing which is often ignored in silk manufacturing. The silkworms are killed in the manufacturing process. Several alternatives are available owing to the innovations introduced by technological upgradation. These alternatives include use of polyester and many other s including spider silk. The primary alternative is the use of wild silk in which the moth is allowed to emerge from its cocoon. Tasar, Eri and Muga belong to the wild silk category. Another alternative is the use of artificial 'spider silk'. It is known for its high durability and carry significance in manufacturing of bulletproof vests and telescopes. As it is artificial, this implies that it is man made in a laboratory by spinning of fermented solution of yeast, sugar, salt and water through a spinning machine. The energy consumption is comparatively higher but the production is also on a large scale and consumes less time. Lotus Silk is another alternative which is manufactured by using the long roots of the lotus flower. These roots are spinned to prepare the fabric. It does not involve any use of chemical preparations and does not leave any carbon footprint, but this fabric is costly and rare.

The other sustainability concerns including energy consumption, water consumption and use of chemical preparations can be addressed by rational use of resources and opting for the organic route. Silk manufacturing is generally not considered to be much harmful for the nature yet there are negative aspects involved which have been discussed previously and can be dealt with accordingly.

The recent data signifies that silk manufacturing segment is a flourishing sector with high profit potential. The largest produce is of mulberry silk as compared to other alternatives which are more sustainable. It is a lever which has profitability on one side and ethical sustainability on the other. The lever is inclined more towards the profitable 


\title{
International Advanced Research Journal in Science, Engineering and Technology
}

\author{
Vol. 8, Issue 10, October 2021
}

\section{DOI: $10.17148 /$ IARJSET.2021.81029}

alternative. New technical innovations can lead to invention of more sustainable alternatives because at the ground level, the unorganized part of the market is flooded with replacements of original silk which are more economical relatively. This signifies that if the sustainable alternatives are economical enough to attract the masses, they could be able to capture a substantial part of the market.

\section{CONCLUSION}

Silk segment of India is a highly potential sector with enormous scope in domestic and international sector. It posses certain benefits which are of great significance for the economy but high profitability does not imply sustainability. There are ill effects of silk manufacturing as well. Silk is considered as a lustrous fabric but it includes many environmental issues. It can be concluded that silk has a sort of mixed impact on the environment which can be tackled if given due consideration. The sustainable alternatives are existent but are costly which hampers their share in the market. The growth prospects in the market for sustainable alternatives are relatively less but it could be increased by introducing more environment friendly and consumer friendly alternatives.

\section{REFERENCES}

Brundtland, G. H. (1987). Report of the World Commission on environment and development:"our common future.".United Nations. Banday, S. (2003) SERI culture - Its Development and Future prospects", Jammu, Vinod Publishers and Distributors

Central Silk Board. ya-silk/SERI Business Manual - A user's

guide (Farm sector). http://www.csb.gov.in/silksERIculture/silk/van

Prakash C., Matthes A. (2021) Cruelty-Free Silk and Guilt-Free Fashion. In: Matthes A., Beyer K., Cebulla H., Arnold M.G., Schumann A. (eds) Sustainable Textile and Fashion Value Chains. Springer, Cham. https://doi.org/10.1007/978-3-030-22018-1 4

Ravikumar, Anitha. (2011). INDIAN SILK INDUSTRY IN THE GLOBAL SCENARIO. 1. 100-110.

Thangavel, Karthik \& Rathinamoorthy, R.. (2017). Sustainable silk production. 10.1016/B978-0-08-102041-8.00006-8. 